\title{
Functional analysis and clinical significance of sodium iodide symporter expression in gastric cancer
}

\author{
Atsushi Shiozaki ${ }^{1}$-Yosuke Ariyoshi ${ }^{1} \cdot$ Daisuke litaka $^{1} \cdot$ Toshiyuki Kosuga $^{1} \cdot$ Hiroki Shimizu $^{1,2} \cdot$ Michihiro Kudou $^{1}$. \\ Tomoki Konishi $^{1} \cdot$ Katsutoshi Shoda $^{1} \cdot$ Tomohiro Arita $^{1} \cdot$ Hirotaka Konishi $^{1}$. Shuhei Komatsu ${ }^{1} \cdot$ Takeshi Kubota $^{1}$. \\ Hitoshi Fujiwara ${ }^{1} \cdot$ Kazuma Okamoto $^{1} \cdot$ Mitsuo Kishimoto $^{3} \cdot$ Eiichi Konishi $^{3} \cdot$ Yoshinori Marunaka $^{4,5}$. \\ Daisuke Ichikawa ${ }^{1,2} \cdot$ Eigo Otsuji ${ }^{1}$
}

Received: 7 May 2018 / Accepted: 3 September 2018 / Published online: 6 September 2018

(c) The International Gastric Cancer Association and The Japanese Gastric Cancer Association 2018

\begin{abstract}
Background Recent studies have described important roles for the sodium iodide symporter (NIS) in tumor behavior. The objectives of the present study were to investigate the role of NIS in the regulation of genes involved in tumor progression and the clinicopathological significance of its expression in gastric cancer (GC).

Methods In human GC cell lines, knockdown experiments were conducted using NIS siRNA, and the effects on proliferation, survival, and cellular movement were analyzed. The gene expression profiles of cells were examined using a microarray analysis. An immunohistochemical analysis was performed on 145 primary tumor samples obtained from GC patients. Results NIS was strongly expressed in MKN45 and MKN74 cells. The depletion of NIS inhibited cell proliferation, migration, and invasion and induced apoptosis. The results of the microarray analysis revealed that various interferon (IFN) signaling-related genes, such as STAT1, STAT2, IRF1, and IFIT1, were up-regulated in NIS-depleted MKN45 cells. Furthermore, the down-regulation of NIS affected the phosphorylation of MAPKs and NF-kB. Immunohistochemical staining showed that NIS was primarily located in the cytoplasm or cell membranes of carcinoma cells, and its expression was related to the histological type or venous invasion. Prognostic analyses revealed that the strong expression of NIS was associated with shorter postoperative survival.

Conclusions These results suggest that NIS regulates tumor progression by affecting IFN signaling, and that its strong expression is related to a worse prognosis in patients with GC. These results provide an insight into the role of NIS as a mediator and/or a biomarker for GC.
\end{abstract}

Keywords NIS · Gastric cancer $\cdot$ IFN $\cdot$ MAPK $\cdot$ NF-kB

Atsushi Shiozaki and Yosuke Ariyoshi contributed equally to this work.

Electronic supplementary material The online version of this article (https://doi.org/10.1007/s10120-018-0874-2) contains supplementary material, which is available to authorized users.

Atsushi Shiozaki

shiozaki@koto.kpu-m.ac.jp

1 Division of Digestive Surgery, Department of Surgery, Kyoto Prefectural University of Medicine, 465 Kajii-cho, Kamigyo-ku, Kyoto 602-8566, Japan

2 Department of Gastrointestinal, Breast and Endocrine Surgery, Faculty of Medicine, University of Yamanashi, Chuo 409-3898, Japan

\section{Introduction}

The sodium iodide symporter (NIS) is a transmembrane glycoprotein with 13 transmembrane domains, belonging to the solute carrier family 5 (SLC5) [1,2]. It transports two $\mathrm{Na}^{+}$for every $\mathrm{I}^{-}$into the cell through the membrane in a manner that

3 Department of Pathology, Kyoto Prefectural University of Medicine, Kyoto 602-8566, Japan

4 Departments of Molecular Cell Physiology and Bio-Ionomics, Graduate School of Medical Science, Kyoto Prefectural University of Medicine, Kyoto 602-8566, Japan

5 Japan Institute for Food Education and Health, St. Agnes' University, Kyoto 602-8013, Japan 
depends on the $\mathrm{Na}^{+}$gradient [3]. In the thyroid, the strong expression of NIS is required in the basolateral membrane for the efficient uptake of $\mathrm{I}^{-}$by thyrocytes [3]. The transcription and translocation of NIS in the thyroid are regulated by thyroid-stimulating hormone (TSH). Furthermore, NIS plays an essential role in the establishment of an $\mathrm{I}^{-}$gradient in thyrocytes, and thus, the synthesis of thyroid hormones is achieved [3-5].

Regarding extra thyroidal tissues, NIS is known to function in salivary glands, the stomach, and intestines [3]. While NIS is expressed on the basolateral membrane in salivary ductal cells and gastric mucosa cells, it is present on the apical side of the epithelium of the small intestine. $\mathrm{I}^{-}$in food and water is absorbed by the intestines and transferred into the circulation $[6,7]$. In contrast, salivary glands and the stomach transfer $\mathrm{I}^{-}$from the bloodstream into the gastrointestinal tract.

In the past decade, several studies reported the overexpression of NIS in thyroid cancer and its oncogenic effects $[8,9]$. By taking advantage of its overexpression in cancer cells, the potential application of radioiodide therapy has been investigated for the targeting of thyroid cancer [10]. Many studies have also investigated the roles of NIS in various cancers, including extrathyroidal cancers such as breast cancer [11], ovarian cancer [12], cervical cancer [13], prostate cancer [14], testicular cancer [15], colon cancer [16], and pancreatic cancer [17]. However, the roles of NIS in tumor progression in gastric cancer (GC) cells and the clinical significance of its expression in patients with GC remain unclear.

We previously investigated the functions of various ion channels and transporters in gastrointestinal cancers [18-22], and indicated that these cellular physiological factors are effective biomarkers and also that their regulation may result in the development of novel strategies for therapies [23]. The objectives of the present study were to clarify the roles of NIS in the regulation of genes involved in tumor progression and the clinicopathological significance of its expression in GC. A microarray analysis showed that the depletion of NIS with siRNA changed the expression levels of many genes involved in interferon (IFN) signaling. We also analyzed the expression of NIS in human GC samples and investigated its relationship with the clinicopathological features and prognosis of GC patients. Our results indicate that NIS plays a crucial role in the tumor progression of GCs.

\section{Materials and methods}

\section{Cell lines, antibodies, and other reagents}

The human GC cell lines KATOIII, HGC27, NUGC4, MKN45, and MKN74 and fibroblast cell line WI-38 were obtained from the Riken Cell Bank (Tsukuba, Japan). The human normal mesothelial cell line MeT-5A (CRL-9444) was purchased from ATCC (Manassas, VA, USA). These cells were grown in RPMI-1640 medium (Nacalai Tesque, Kyoto, Japan) supplemented with $100 \mathrm{U} / \mathrm{ml}$ of penicillin, $100 \mu \mathrm{g} / \mathrm{ml}$ of streptomycin, and $10 \%$ fetal bovine serum (FBS). Cells were cultured in flasks or dishes in a humidified incubator at $37{ }^{\circ} \mathrm{C}$ under $5 \% \mathrm{CO}_{2}$ in air.

The monoclonal anti-NIS antibody used in the immunohistochemical analysis was obtained from Thermo Fisher Scientific (Massachusetts, USA). The rabbit monoclonal c-Jun N-terminal kinase (JNK), phosphorylated JNK, extracellular signal-regulated kinase (ERK), phosphorylated ERK, p38, phosphorylated p38, NF-кB, phospho$\mathrm{NF}-\kappa \mathrm{B}$, and cleaved caspase 3 antibodies were purchased from Cell Signaling Technology (Beverly, MA). Rabbit polyclonal antibodies against GAPDH were purchased from Santa Cruz Biotechnology (Santa Cruz, CA). Horseradish peroxidase (HRP)-conjugated anti-rabbit or mouse secondary antibodies was purchased from Cell Signaling Technology (Beverly, MA). Human Stomach Total RNA was purchased from Clontech Laboratories, Inc (Mountain View, CA).

\section{Real-time reverse transcription-polymerase chain reaction (RT-PCR)}

Total RNA was extracted using an RNeasy kit (Qiagen, Valencia, CA). Messenger RNA (mRNA) expression was measured by quantitative real-time PCR (7300 Real-Time PCR System; Applied Biosystems, Foster City, CA) with TaqMan Gene Expression Assays (Applied Biosystems), according to the manufacturer's instructions. The expression levels of the following genes were measured: NIS (Hs00166567_m1), STAT1 (Hs01013996_m1), STAT2 (Hs01013115_g1), IRF1 (Hs00971965_m1), and IFIT1 (Hs03027069_s1) (Applied Biosystems). Expression was normalized for each gene to the housekeeping gene betaactin (ACTB, Hs01060665_g1; Applied Biosystems). Assays were performed in triplicate.

\section{siRNA transfection}

Cells were transfected with $12 \mathrm{nmol} / \mathrm{l}$ NIS siRNA (Stealth RNAiTM siRNA \#HSS 109847; Invitrogen, Carlsbad, CA) using the Lipofectamine RNAiMAX reagent (Invitrogen), according to the manufacturer's instructions. Medium containing siRNA was replaced with fresh medium after $24 \mathrm{~h}$. The control siRNA provided (Stealth RNAiTM siRNA Negative Control; Invitrogen) was used as a negative control. 


\section{Overexpression study}

Control-HaloTag ${ }^{\circledR}$ plasmid (Promega, G6591) and NISHaloTag ${ }^{\circledR}$ plasmid were transfected into MKN45 cells using FuGENE HD transfection reagents (Promega, E2311) following the manufacturer's instructions. Transfection of vector was confirmed by fluorescent microscopy for HaloTag ${ }^{\circledR}$ fusion protein stained with the TMR conjugated HaloTag ${ }^{\circledR}$ ligand (Promega, G8252) according to the manufacturer's protocol. After passaging cells, NIS-expressing cells were used for proliferation and migration assays.

\section{Cell proliferation}

Cells were seeded on 6-well plates at a density of 3.0 $\times 10^{4}$ cells per well and incubated at $37{ }^{\circ} \mathrm{C}$ with $5 \% \mathrm{CO}_{2}$. siRNA was transfected $24 \mathrm{~h}$ after the cells had been seeded. Cells were detached from the flasks with trypsin-EDTA 48 and $72 \mathrm{~h}$ after siRNA transfection and were counted using a hemocytometer.

\section{Cell cycle analysis}

The cell cycle phase was evaluated $48 \mathrm{~h}$ after siRNA transfection by flow cytometry. Briefly, cells were detached from the flasks by a trypsin-EDTA treatment, and nuclear isolation medium (NIM-DAPI 10, Beckman Coulter, Fullerton, CA, USA) was added to the cell pellets to stain cells. At least 10,000 cells were analyzed using Cell Lab Quanta (Beckman Coulter), and FlowJo software was used to assess cell cycle distribution.

\section{Analysis of apoptotic cells}

Cells were harvested $48 \mathrm{~h}$ after siRNA transfection and stained with fluorescein isothiocyanate-conjugated annexin $\mathrm{V}$ and phosphatidylinositol using the annexin V kit (Beckman Coulter, Brea, CA) according to the manufacturer's protocol. The proportion of apoptotic cells was analyzed by flow cytometry with BD Accuri C6 (BD Biosciences).

\section{Analysis of cell migration and invasion}

The migration assay was conducted using a Cell Culture Insert with a pore size of $8 \mu \mathrm{m}$ (BD Biosciences). Biocoat Matrigel (BD Biosciences) was used to evaluate cell invasion potential. Briefly, cells $\left(7.5 \times 10^{4}\right.$ cells per well $)$ were seeded in the upper chamber in serum-free medium $24 \mathrm{~h}$ after siRNA transfection. The lower chamber contained medium with $10 \%$ FBS. The chambers were incubated at $37{ }^{\circ} \mathrm{C}$ for $48 \mathrm{~h}$ in $5 \% \mathrm{CO}_{2}$, and non-migrated or non-invaded cells were then removed from the upper side of the membrane by scrubbing with cotton swabs. Migrated or invaded cells were fixed on the membrane and stained with Diff-Quick staining reagents (Sysmex, Kobe, Japan). The migrated or invaded cells on the lower side of the membrane were counted in four independent fields of view at $100 \times$ magnification for each insert. Each assay was performed in triplicate.

\section{Microarray sample preparation and hybridization}

Total RNA was extracted using an RNeasy kit (Qiagen). RNA quality was monitored with an Agilent 2100 Bioanalyzer (Agilent Technologies, Santa Clara, CA). Cyanine-3 (Cy3)-labeled cRNA was prepared from $0.1 \mu \mathrm{g}$ of total RNA using a Low Input Quick Amp Labeling Kit (Agilent), according to the manufacturer's instructions. Samples were purified using RNeasy columns (Qiagen). A total of $0.60 \mu \mathrm{g}$ of Cy3-labeled cRNA was fragmented and hybridized to an Agilent SurePrint G3 Human Gene Expression $8 \times 60 \mathrm{~K}$ ver 2.0 Microarray for $17 \mathrm{~h}$. Slides were washed and scanned immediately on an Agilent DNA Microarray Scanner (G2565CA) using the one color scan setting for $8 \times 60 \mathrm{~K}$ array slides.

\section{Processing of microarray data}

Scanned images were analyzed with Feature Extraction Software 11.5.1.1 (Agilent) using default parameters to obtain background-subtracted and spatially detrended Processed Signal intensities. Signal transduction networks were analyzed using Ingenuity Pathway Analysis (IPA) software (Ingenuity Systems, Inc., Redwood City, CA).

\section{Western blotting}

Cells were harvested in M-PER lysis buffer (Pierce, Rockford, IL) supplemented with protease inhibitors (Pierce). Protein concentrations were measured with a modified Bradford assay (Bio-Rad, Hercules, CA). Cell lysates containing equal amounts of total protein were separated by SDS-PAGE and then transferred onto PVDF membranes (GE Healthcare, Piscataway, NJ). These membranes were then probed with the indicated antibodies, and proteins were detected using an ECL Plus Western Blotting Detection System (GE Healthcare).

\section{Patients and primary tissue samples}

Primary tumor samples of GC were obtained from 145 consecutive GC patients who had undergone curative gastrectomy at the Division of Digestive Surgery, Department of Surgery, Kyoto Prefectural University of Medicine (Kyoto, Japan) between 2001 and 2003. Each sample was embedded in paraffin after $24 \mathrm{~h}$ of formalin fixation. Relevant clinical and survival data were available for all patients. Written 
consent was always obtained in the formal style and after approval by the local Ethics Committee. None of these patients had undergone endoscopic mucosal resection, palliative resection, preoperative chemotherapy, or radiotherapy, and none had synchronous or metachronous multiple cancers in other organs. The disease clinical and pathological stages were defined in accordance with the International Union Against Cancer tumor-lymph node-metastases (TNM) classification [24].

\section{Immunohistochemistry}

Paraffin sections (thickness of $4 \mu \mathrm{m}$ ) of tumor tissues were subjected to immunohistochemical staining for the NIS protein using the avidin-biotin-peroxidase method. Briefly, paraffin sections were dewaxed with xylene and hydrated with a graded series of alcohols. Endogenous peroxidases were quenched by incubating the sections for $30 \mathrm{~min}$ in $0.3 \% \mathrm{H}_{2} \mathrm{O}_{2}$. An Avidin/Biotin Blocking Kit was used to block endogenous biotin, biotin receptors, and avidin binding sites (Vector laboratories, Burlingame, CA). Sections were then treated with a protein blocker and incubated at $4{ }^{\circ} \mathrm{C}$ overnight with the anti-NIS antibody. The avidin-biotin-peroxidase complex (Vectastain ABC Elite kit; Vector Laboratories, Burlingame, CA) was visualized with diaminobenzidine tetrahydrochloride. Sections were counterstained with hematoxylin, dehydrated with a graded series of alcohols, cleared in xylene, and mounted.

Immunohistochemical samples stained with NIS were graded semi-quantitatively by considering both the staining intensity and percentage of positive tumor cells using an immunoreactive score (IRS) [25]. Staining intensity was scored as 0 (no staining), 1 (weak staining), 2 (moderate staining), or 3 (strong staining). The proportion of positive tumor cells was scored from 0 to 1.0. The score of each sample was calculated as the maximum multiplied product of the intensity and proportion scores (0 to 3.0). The NIS score varied widely between tumors. The minimum NIS score was 0.1 , while the maximum was 2.1 (median $=0.7$; mean \pm standard deviation $(\mathrm{SD})=0.73 \pm 0.41)$. The cut-off value of patients divided into two groups for NIS score was determined as the value which 5-year overall survival rate between two groups was the most different. We showed 5 -year overall survival rate with each cut-off values in Supplementary Table 1.

\section{Statistical analysis}

The chi-squared test was used to assess differences between proportions, and Student's $t$ tests (for comparisons between two groups) were used to evaluate continuous variables. Survival curves were constructed by the Kaplan-Meier method, and differences in survival were examined using the
Log-rank test. A multivariate analysis of the factors influencing survival was performed using Cox's proportional hazard model. Differences were considered to be significant when the relevant $p$ value was $<0.05$. These analyses were performed using the statistical software JMP (version 10, SAS Institute Inc., Cary, NC).

\section{Results}

\section{Expression of NIS in GC cells}

To clarify the role of NIS in GC, we examined 5 GC cell lines: KATOIII, HGC27, NUGC4, MKN45, and MKN74, for NIS mRNA expression. Quantitative RT-PCR of these cell lines showed that NIS mRNA was strongly expressed in NUGC4, MKN45, and MKN74 cells (Fig. 1a). Expression of NIS mRNA was quite weak in fibroblast cell line WI-38, and mesothelial cell line MeT-5A (Supplementary Fig. 1a). Human Stomach Total RNA was analyzed, and its high expression was observed (Supplementary Fig. 1b).

\section{NIS regulates cell proliferation in GC cells}

We conducted knockdown experiments using NIS siRNA in MKN45 and MKN74 cells and investigated the effects of NIS depletion on cell proliferation. NIS siRNA effectively reduced NIS mRNA levels (Fig. 1b) in both cell lines. In both cells, the cell counts of NIS-depleted cells were significantly lower than those of control siRNA-transfected cells $72 \mathrm{~h}$ after siRNA transfection (Fig. 1c). The down-regulation of NIS partially reduced cell cycle progression from the $\mathrm{G}_{1}$ to $\mathrm{S}$ phase in MKN45 and MKN74 cells (Fig. 1d). These results suggest that NIS plays an essential role in regulating cell cycle progression and cell proliferation in GC cells.

\section{NIS controls the survival of GC cells}

To clarify the role of NIS in GC cell survival, we treated MKN45 and MKN74 cells with NIS siRNA and analyzed apoptosis. The down-regulation of NIS induced early apoptosis (annexin V-positive/PI-negative) in MKN45 and MKN74 cells $48 \mathrm{~h}$ after siRNA transfection (Fig. 2a). Furthermore, NIS siRNA enhanced staurosporine stimulusinduced early apoptosis in both cells (Fig. 2a). These results indicate that the expression of NIS influences cell survival in GC cells.

\section{NIS controls cell migration and invasion in GC cells}

We analyzed the effects of the knockdown of NIS on cell migration and invasion in GC cells. In MKN45 and MKN74 cells, NIS siRNA significantly inhibited cell migration and 

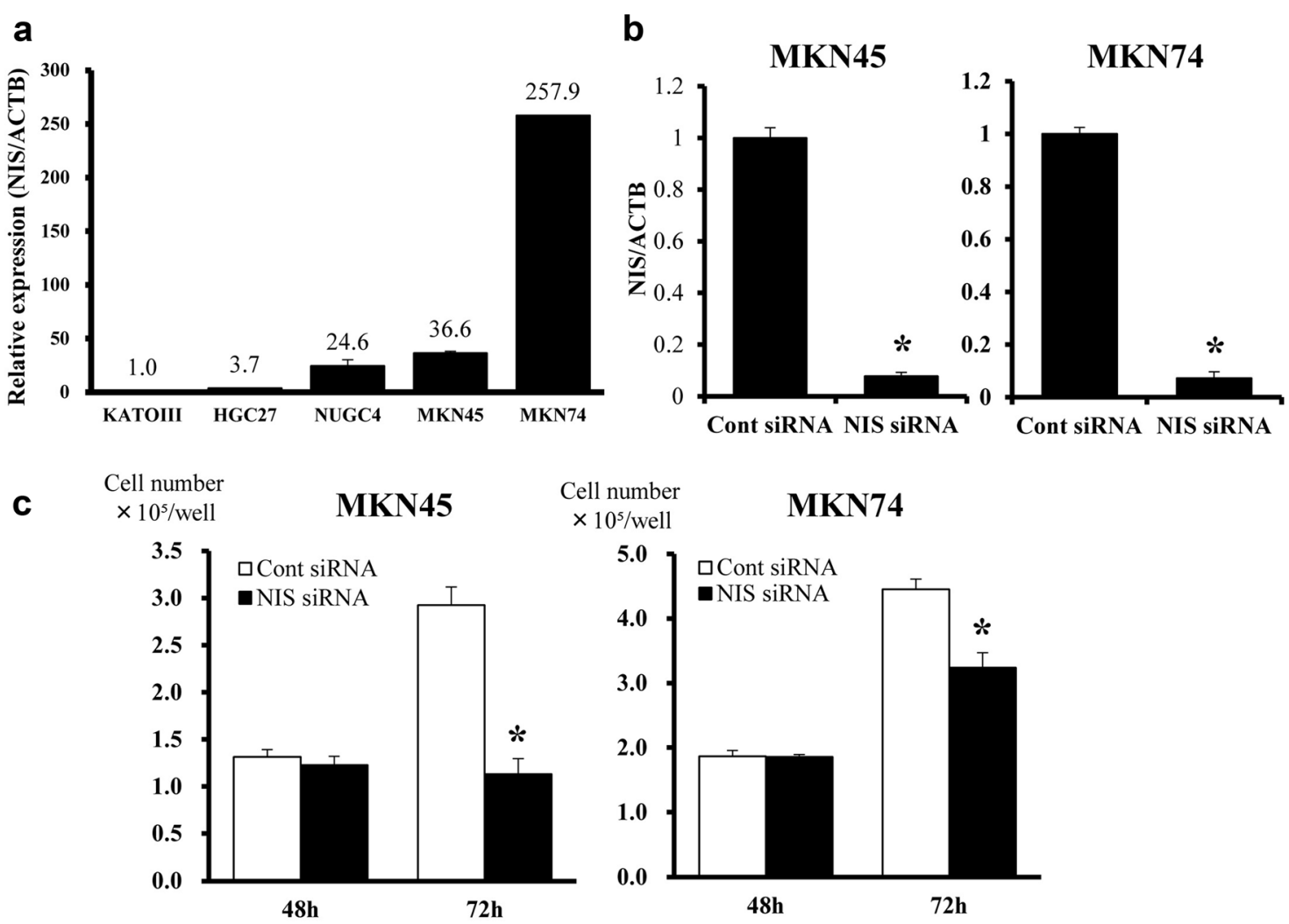

d
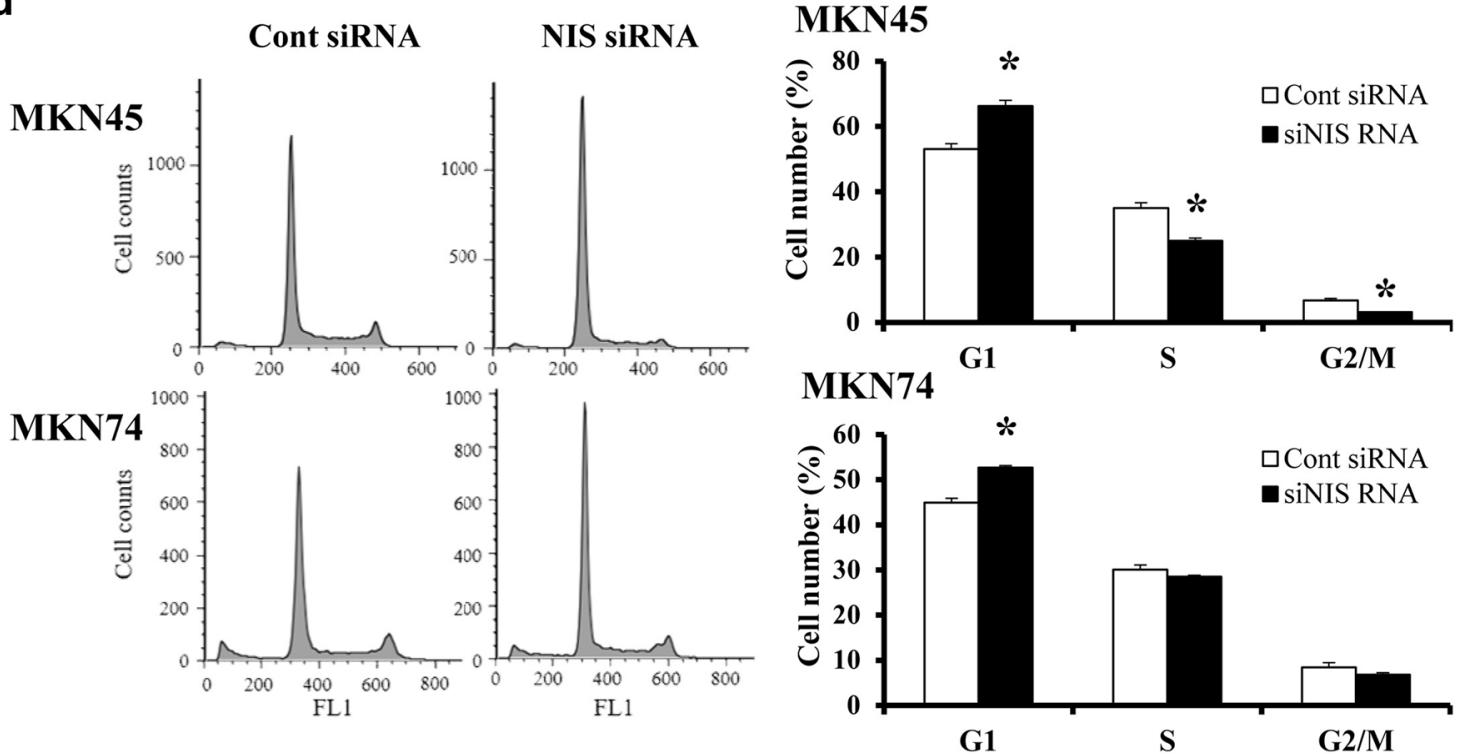

Fig. 1 NIS controls the cell cycle progression of GC cells. a NIS mRNA expression was analyzed in 5 GC cell lines. Quantitative RT-PCR showed that mRNA was strongly expressed in NUGC4, MKN45, and MKN74 cells. b NIS siRNA effectively reduced NIS mRNA levels in MKN45 and MKN74 cells. Mean \pm SEM. $n=3$. $* p<0.05$ (significantly different from control siRNA). c The downregulation of NIS inhibited the proliferation of MKN45 and MKN74 cells. The number of cells was counted 48 and $72 \mathrm{~h}$ after siRNA transfection. Mean \pm SEM. $n=4 . * p<0.05$ (significantly different from control siRNA). $\mathbf{d}$ The down-regulation of NIS partially reduced cell cycle progression from the $G_{1}$ to $S$ phase in MKN45 and MKN74 cells. Cells transfected with control or NIS siRNA were stained with propidium iodide (PI) and analyzed by flow cytometry. Mean \pm SEM. $n=3$. $* p<0.05$ (significantly different from control siRNA) 

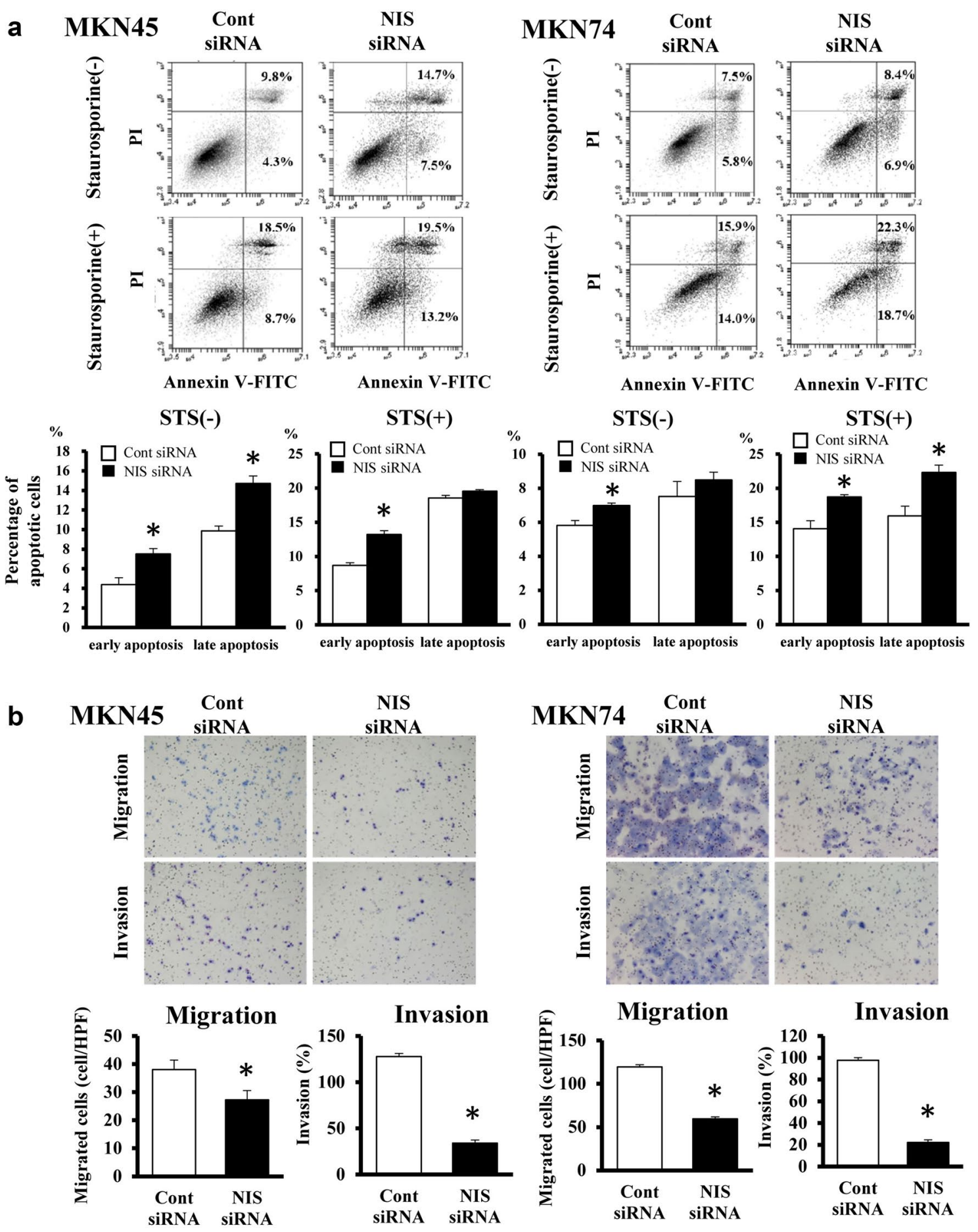

Fig. 2 NIS controls the survival, migration and invasion of GC cells. a The down-regulation of NIS induced early apoptosis, and enhanced staurosporine (STS)-induced early apoptosis in MKN45 and MKN74 cells. Apoptosis was assessed by flow cytometry using PI/annexin V double staining. Mean \pm SEM. $n=3$. $* p<0.05$ (significantly differ-

invasion (Fig. 2b). These results suggest that NIS plays an important role in regulating cell migration and invasion in GC cells. ent from control siRNA). b The down-regulation of NIS inhibited the migration and invasion of MKN45 and MKN74 cells. Cell migration and invasion were examined using the Boyden chamber assay. Mean \pm SEM. $n=3$. ${ }^{*} p<0.05$ (significantly different from control siRNA)

We also conducted overexpression study in MKN45 cells (Supplementary Figs. 2, 3). Cells transfected Control-HaloTag ${ }^{\circledR}$ plasmid and NIS-HaloTag ${ }^{\circledR}$ plasmid were 
stained in red (Supplementary Fig. 2a), and NIS plasmid increased NIS mRNA levels (Supplementary Fig. 2b). In contrast to knockdown experiments, NIS overexpression in MKN45 cells did not decrease cell growth and cellular movement (Supplementary Fig. 3a, c). Interestingly, NIS overexpression in MKN45 cells tended to decrease early apoptosis (Supplementary Fig. 3b) as opposed to knockdown of NIS.

\section{Gene expression profiles of NIS-depleted GC cells}

We analyzed the gene expression profiles of NIS-depleted MKN45 cells in microarray and bioinformatics studies. The results of the microarray analysis showed that the expression levels of 3316 genes displayed fold changes of $>2.0$ in MKN45 cells upon the depletion of NIS. Among these genes, 1618 were up-regulated and 1698 were downregulated in NIS siRNA-depleted MKN45 cells. A list of 10 genes with expression levels that were the most strongly up- or down-regulated in NIS-depleted MKN45 cells is shown in Table 1. An Ingenuity Pathway Analysis (IPA) showed that "Cell Death and Survival", "Cellular Movement", and "Cellular Growth and Proliferation" were the top-ranking "Molecular and Cellular Functions" related to NIS depletion (Supplementary Table 2), and these were consistent with the results obtained in our in vitro studies.

\section{Signal pathways and molecular mechanisms regulated by NIS in GC cells}

We then examined the signal transduction networks induced by NIS depletion using IPA, and found that "Interferon Signaling" was the top-ranking canonical pathway related to the depletion of NIS (Supplementary Table 3). An analysis of the map of this pathway revealed that STAT pathway-related genes were strongly up-regulated by the depletion of NIS (Fig. 3a).

To confirm the results of the microarray analysis, several genes included in the "interferon signaling" pathway map (Fig. 3a) were examined in more detail using quantitative RT-PCR. STAT1, STAT2, IRF1, and IFIT1 mRNA expression levels were higher in NIS-depleted MKN45 cells than in control siRNA-transfected cells (Fig. 3b). Similar results were obtained for the MKN74 cell line (Fig. 3b).

Recent studies indicated that IFN signaling engages multiple pathways including the STAT signaling, Mitogenactivated Protein Kinase (MAPK), and NF-kB pathways [26, 27]. Therefore, we investigated the effects of the knockdown of NIS on their expression and phosphorylation by Western blotting. The down-regulation of NIS affected the phosphorylation of p38, JNK, Erk 1/2, and NF-kB in MKN45 and MKN74 cells (Fig. 3c). Furthermore, the down-regulation of NIS increased cleaved caspase 3 in both cell lines (Fig. 3c). These results were consistent with those of the microarray
Table 1 Ten genes displaying the greatest change in expression levels in NISdepleted MKN45 cells

\begin{tabular}{lllc}
\hline Gene symbol & Unigene ID & Gene name & Fold change \\
\hline Up-regulated & & & \\
RTP4 & Hs.43388 & Receptor (chemosensory) transporter protein 4 & 77.451 \\
IFI44L & Hs.744918 & Interferon-induced protein 44-like & 59.888 \\
IFIT1 & Hs.20315 & Interferon-induced protein with tetratricopeptide repeats 1 & 55.599 \\
XAF1 & Hs.441975 & XIAP associated factor 1 & 55.168 \\
IFI6 & Hs.380250 & Interferon, gamma-inducible protein 16 & 49.748 \\
IFI44 & Hs.82316 & Interferon-induced protein 44 & 49.015 \\
IFIT3 & Hs.744072 & Interferon-induced protein with tetratricopeptide repeats 3 & 46.933 \\
OAS2 & Hs.414332 & 2'-5'-Oligoadenylate synthetase 2 & 43.365 \\
LHCGR & Hs.468490 & Luteinizing hormone/choriogonadotropin receptor & 42.247 \\
SAMD9L & Hs.489118 & Sterile alpha motif domain containing 9-like & 43.628 \\
Down-regulated & & & \\
EGR3 & Hs.534313 & Early growth response 3 & -18.106 \\
SSX7 & Hs.558712 & Synovial sarcoma, X breakpoint 7 & -15.384 \\
C12orf50 & Hs.112930 & Chromosome 12 open reading frame 50 & -13.436 \\
RNU4ATAC & Hs.689638 & RNA, U4atac small nuclear (U12-dependent splicing) & -12.899 \\
LOC100506136 & Hs.729869 & Uncharacterized LOC100506136 & -12.588 \\
LRRC38 & Hs.657356 & Leucine-rich repeat containing 38 & -12.485 \\
CRIP2 & Hs.534309 & Cysteine-rich protein 2 & -12.132 \\
SERTAD4-AS1 & Hs.446946 & SERTAD4 antisense RNA 1 & -11.402 \\
IGFBP1 & Hs.642938 & Insulin-like growth factor binding protein 1 \\
LOC100505622 & Hs.661761 & Uncharacterized LOC100506136 & -10.86 \\
\hline
\end{tabular}


a

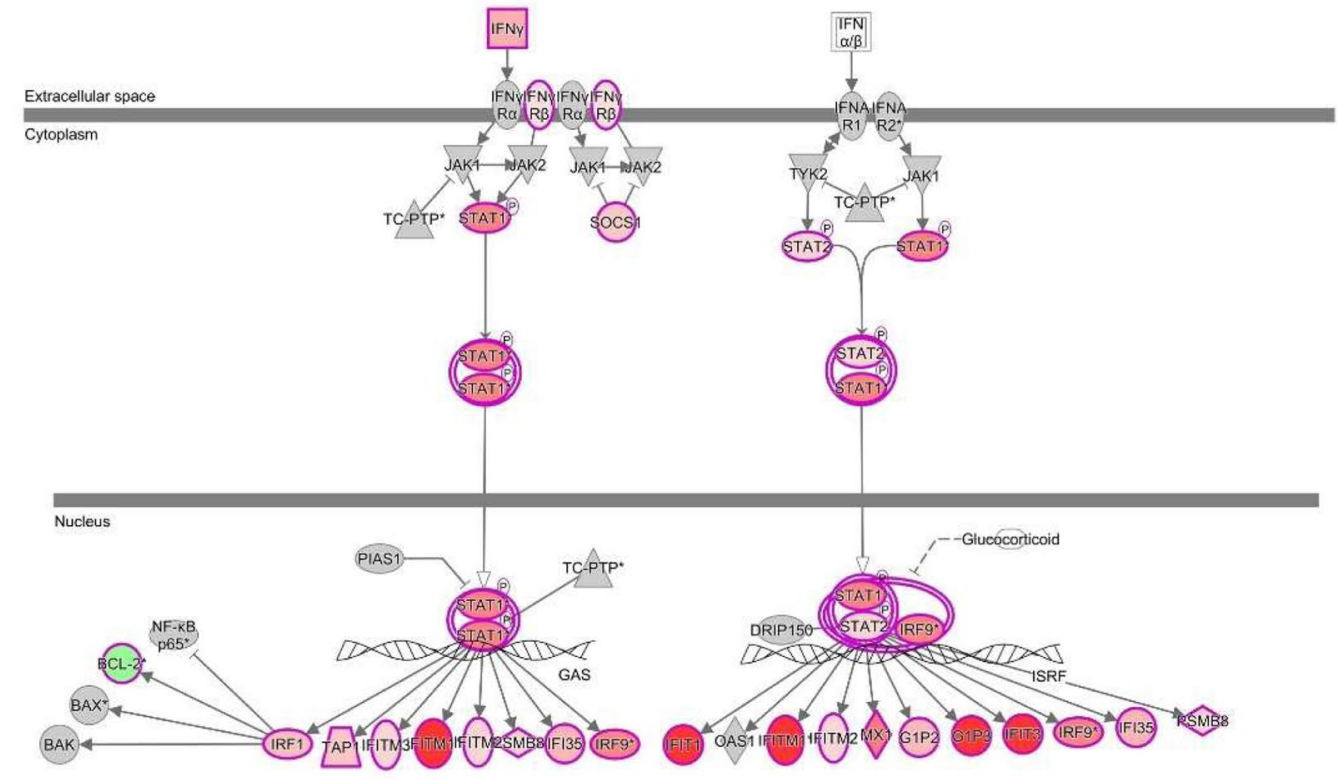

b

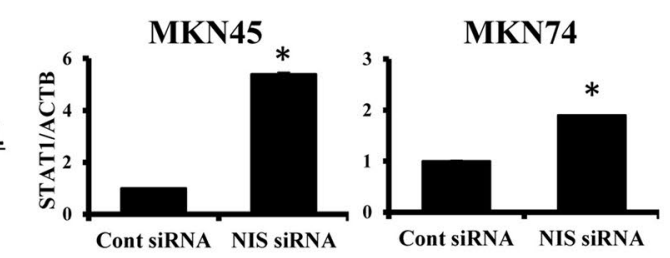

C

STAT1

STAT2
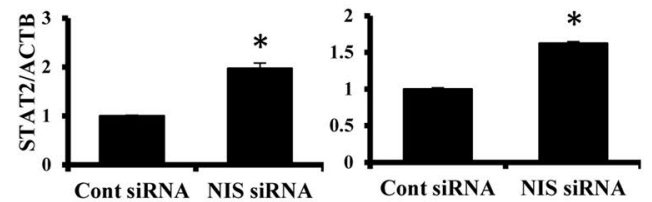

IRF1
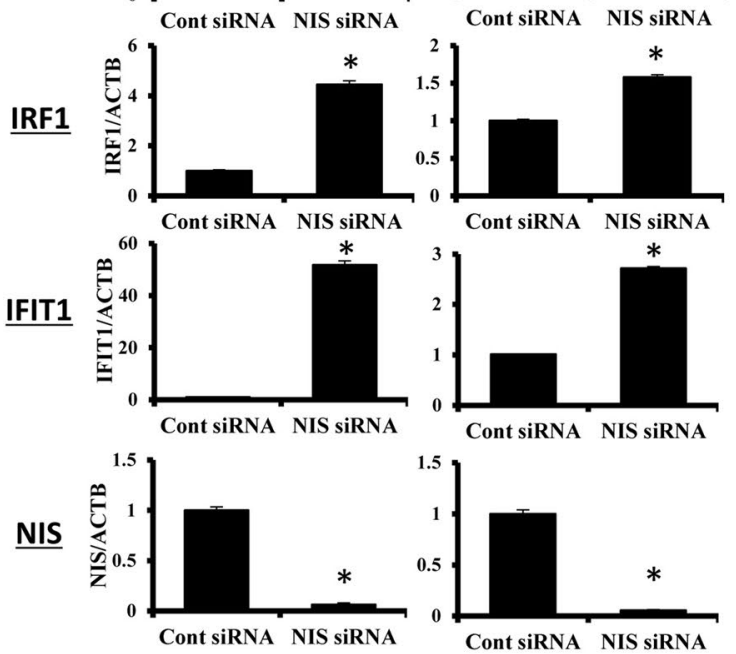

Fig. 3 Signal pathways regulated by NIS in GC cells. a The signaling map of "interferon signaling", top-ranking canonical pathways related to NIS depletion according to an ingenuity pathway analysis. Red and green indicate genes with expression levels that were higher or lower, respectively, than reference RNA levels. b Verification of gene expression by real-time quantitative PCR. The expression levels of four selected interferon signaling pathway-related genes (STAT1,

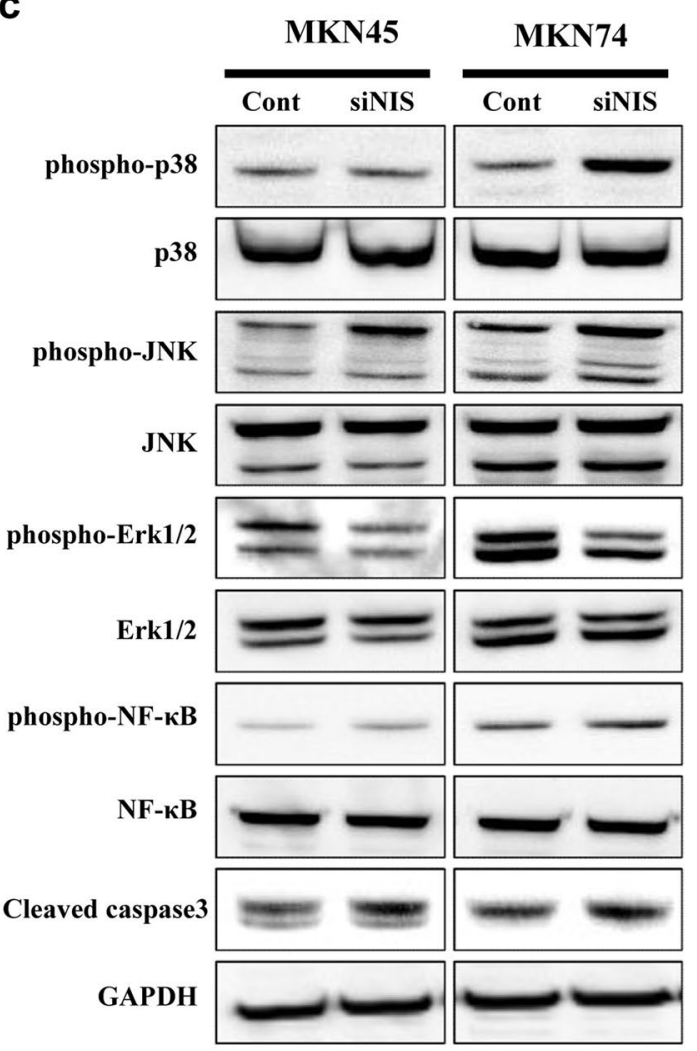

STAT2, IRF1, and IFIT1) in NIS-depleted MKN45 and MKN74 cells were compared to those in control siRNA-transfected cells using realtime quantitative PCR. Mean \pm SEM. $n=3$. $* p<0.05$ (significantly different from control siRNA). $\mathbf{c}$ The down-regulation of NIS affected the phosphorylation of p38, JNK, Erk 1/2, and NF-kB in MKN45 and MKN74 cells. Furthermore, the down-regulation of NIS increased cleaved caspase 3 in both cell lines 
analysis and suggest that the STAT, MAPK, and NF-kB signaling pathways are key mechanisms by which NIS controls cancer cell functions, such as the proliferation, survival, and cellular movement of GC cells.

\section{NIS protein expression in human GCs}

An immunohistochemical examination of non-tumorous gastric tissue performed with the NIS antibody demonstrated that the NIS protein was expressed in the cell membranes of a gastric mucosal cell population (Fig. 4a). NIS expression was more remarkable in foveolar epithelial cells than fundic glands (Supplementary Fig. 4). We examined the expression of NIS in 145 primary tumor samples of human GC based on their immunohistochemical reactivity. The NIS protein was mostly expressed in the cytoplasm or cell membranes of carcinoma cells (Fig. 4b).

Regarding the expression of NIS in tumors, we divided GC patients into 2 groups based on staining scores; a low grade NIS expression group with staining scores $<0.9$, $n=91$, and a high grade NIS expression group with staining scores $\geq 0.9, n=54$ (Fig. $4 \mathrm{c}, \mathrm{d}$ ). The relationships among the expression of NIS and various clinicopathological parameters were analyzed (Table 2). Age, histological type, and venous invasion correlated with the expression of NIS (Table 2). Although 23 cases of mixed histological type GCs were included in the present study (15.9\%), no correlation was found between the NIS expression and the mixed histological type (low grade NIS expression group: 17.6\%, high grade NIS expression group: $13.0 \%, p=0.4563$ ).

We also investigated whether the expression of NIS was prognostic for GC patients after curative resection. The 5-year overall survival rate of the NIS high group was $60.9 \%$, which was significantly poorer than that of the NIS low group (82.9\%) $(p=0.0041)$ (Fig. 4e). A univariate analysis of survival after gastrectomy revealed that age, lymphatic invasion, venous invasion, $\mathrm{pT}, \mathrm{pN}$ category, and NIS expression were significant prognostic factors (Table 3 ). A multivariate analysis with these 6 factors revealed that age, $\mathrm{pT}$, pN category, and NIS expression were independent prognostic factors (Table 3 ). These results suggest that the expression of NIS is induced in GC, and its strong expression may be related to the poor prognosis of patients with GC after curative resection.

\section{Discussion}

NIS has been shown to function in thyroid cells and is upregulated in thyroid cancer and many non-thyroid cancers such as breast cancer [8, 28]. Wapnir et al. [28] analyzed the immunohistochemical profiles of NIS in various cancers using high density tissue microarrays, and detected its expression in 19 carcinomas, including prostate, ovary, lung, and colon cancers. In addition, Riesco-Eizaguirre et al. [12] reported that the strong expression of NIS in ovarian cancer correlated with a poor prognosis, indicating its potential as an effective biomarker. In the present study, we investigated the expression of NIS in GC and examined its relationships with clinicopathological features and prognoses. We found a correlation between the expression of NIS and the histological type or venous invasion. Furthermore, our results showed that the expression of NIS may be a valuable poor prognostic factor for patients with GC.

Our in vitro study revealed that HGC27, undifferentiated GC cell line and KATO-III, signet ring cell carcinoma line were almost negative for NIS (Fig. 1a). Furthermore, results of immunohistochemistry showed that most of undifferentiated GCs belonged to low grade NIS group (Table 2), suggesting that NIS overexpression might be not associated with the development of undifferentiated GCs. On the other hand, our prognostic analysis showed that the strong expression of NIS was associated with poor prognosis of GCs (Table 3). One of the reasons of this inconsistency may be the fact that the histological type was not a prognostic factor in our cohort (Table 3), and we need to state the limitation of this retrospective study related to small sample size and selection bias. However, to the best of our knowledge, this is the first study to examine the prognostic significance of NIS expression in patients with GC and the gene expression profile of NIS-depleted cancer cells.

Several recent studies described important roles for NIS in oncogenesis, independently of its transmembrane transport activity. NIS is localized in the cytoplasm and does not mediate $\mathrm{Na}^{+} / \mathrm{I}^{-}$transport in many carcinomas. Regarding the mechanism by which NIS plays a role in carcinogenesis, Lacoste et al. [29] demonstrated that NIS interacts with the leukemia-associated RhoA guanine exchange factor to activate RhoA, and enhances cell migration and invasion through RhoGTPase signaling. Dentice et al. [30] showed that the transcription factor Nkx-2.5 specifically activated NIS in lactating and breast cancer cells. Riesco-Eizaguirre et al. [12] revealed that estrogen receptor and paired box 8 regulated NIS expression in ovaries and fallopian tubes. In addition, previous studies reported a relationship between major signaling pathways and NIS. For example, in breast cancers, NIS expression is induced by retinoic acid and is regulated by the phosphoinositide-3 kinase (PI3K) and MAPK signaling pathways [31,32]. Our results also revealed that the depletion of NIS affected MAPK and NF-kB signaling, and changed the behaviors of GC cells, such as the cell cycle, survival, and movement. Furthermore, based on the results of gene expression profiles in the present study, we newly demonstrated that IFN signaling is an important network regulated by NIS. 

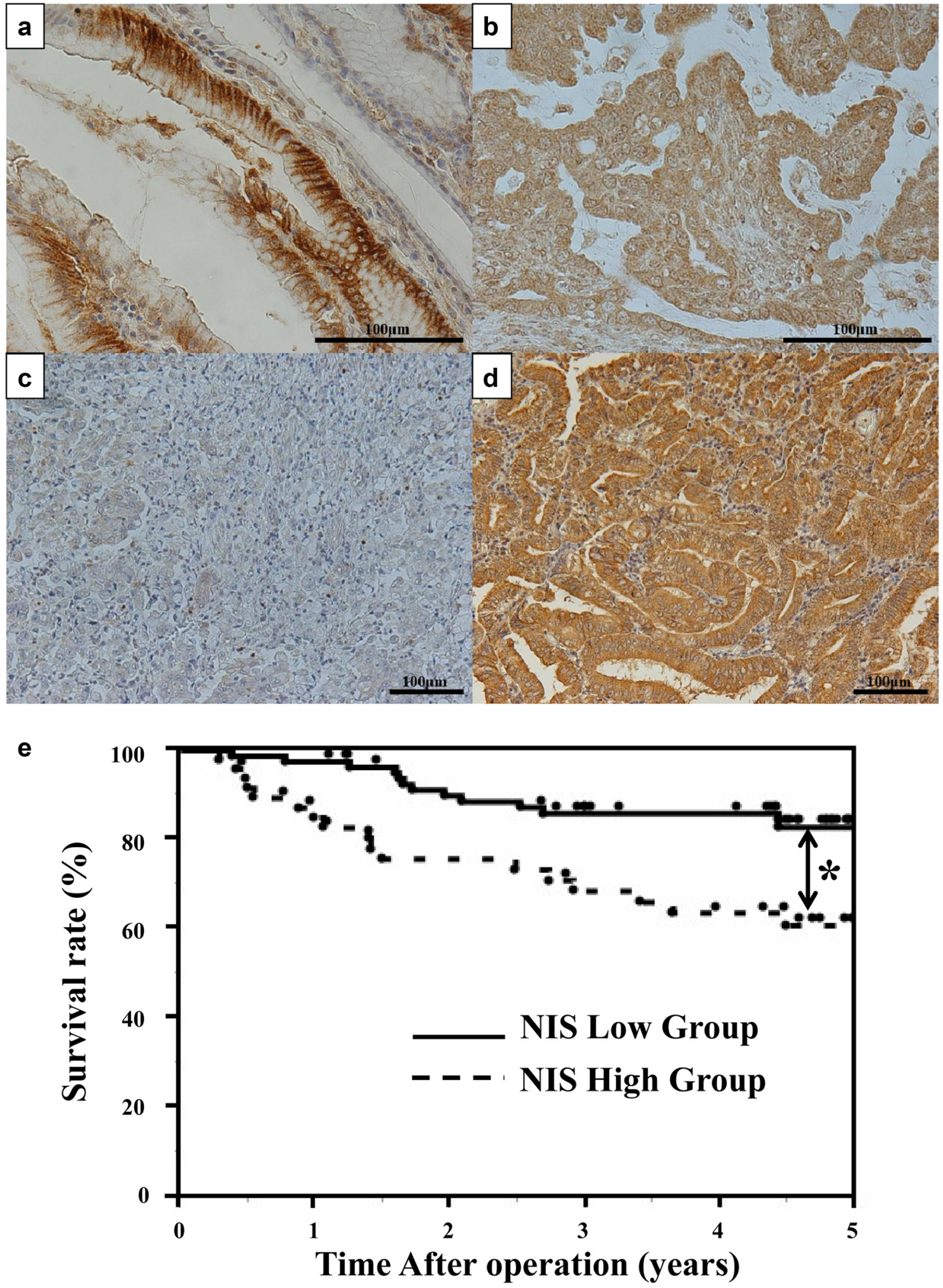

Fig. 4 NIS protein expression in human GCs. a Immunohistochemical staining of human non-tumorous gastric tissue with an NIS antibody. The NIS protein was expressed in the cell membranes of a gastric mucosal cell population. Magnification: $\times 400$. Bar, $100 \mu \mathrm{m}$. b Immunohistochemical staining of primary human GC samples with the NIS antibody. Magnification: $\times 400$. Bar, $100 \mu \mathrm{m}$. c Immunohistochemical staining of primary human GC samples with the low grade expression of NIS. Magnification: $\times 200$. Bar, $100 \mu \mathrm{m}$. d Immunohistochemical staining of primary human GC samples with the high grade expression of NIS. Magnification: $\times 200$. Bar, $100 \mu \mathrm{m}$. e Survival curve of patients after curative resection for $\mathrm{GC}$ according to the expression of NIS. All patients were classified into two groups: the low grade expression of NIS $(n=91)$ and high grade expression of NIS $(n=54)$ in the tumor. ${ }^{*} p<0.05$ : log-rank test 
Table 2 Correlations between clinicopathological features and NIS expression

\begin{tabular}{|c|c|c|c|}
\hline \multirow[t]{2}{*}{ Variables } & \multicolumn{2}{|c|}{ NIS expression } & \multirow[t]{2}{*}{$p$ value } \\
\hline & $\begin{array}{l}\text { Low group } \\
(n=91)\end{array}$ & $\begin{array}{l}\text { High group } \\
(n=54)\end{array}$ & \\
\hline \multicolumn{4}{|l|}{ Gender } \\
\hline Male & 63 & 36 & \multirow[t]{2}{*}{0.7488} \\
\hline Female & 28 & 18 & \\
\hline \multicolumn{4}{|l|}{ Age } \\
\hline$\leq 65$ & 59 & 25 & \multirow[t]{2}{*}{$0.029 *$} \\
\hline$>65$ & 32 & 29 & \\
\hline \multicolumn{4}{|c|}{ Location of the primary tumor } \\
\hline $\mathrm{U}$ & 8 & 11 & \multirow[t]{3}{*}{0.1374} \\
\hline M & 49 & 24 & \\
\hline $\mathrm{L}$ & 34 & 19 & \\
\hline \multicolumn{4}{|l|}{ Histological type } \\
\hline Differentiated & 32 & 39 & \multirow[t]{2}{*}{$0.0001^{*}$} \\
\hline Undifferentiated & 59 & 15 & \\
\hline \multicolumn{4}{|c|}{ Lymphatic invasion } \\
\hline Negative & 52 & 27 & \multirow[t]{2}{*}{0.404} \\
\hline Positive & 39 & 27 & \\
\hline \multicolumn{4}{|l|}{ Venous invasion } \\
\hline Negative & 73 & 30 & \multirow[t]{2}{*}{$0.0017 *$} \\
\hline Positive & 18 & 24 & \\
\hline \multicolumn{4}{|l|}{$\mathrm{pT}$} \\
\hline pT1 & 52 & 30 & \multirow[t]{2}{*}{0.8522} \\
\hline pT2-4 & 39 & 24 & \\
\hline \multicolumn{4}{|l|}{$\mathrm{pN}$} \\
\hline pNO & 62 & 34 & \multirow[t]{2}{*}{0.5258} \\
\hline pN1-3 & 29 & 20 & \\
\hline
\end{tabular}

$p T$ pathological $\mathrm{T}$ stage, $p N$ pathological $\mathrm{N}$ stage

$* p<0.05$ : Chi-squared test

IFN signaling has been investigated because of its importance in defense against infection and cancer, as well as its potential as a therapeutic agent. Recent studies indicated that IFN signaling engages multiple pathways. The JAK-STAT signaling pathway is known to be a key mechanism of IFNmediated gene transcription, and IFNs also modulate several other signaling pathways including the MAPK and NF-kB pathways [26, 27, 33, 34]. An IFN $\gamma$ stimulation was found to induce molecules with adaptor functions, such as MyD88, which is important for signaling through toll-like receptors to activate MAPK and NF-kB pathways $[35,36]$. Our investigation with GC cells showed that the depletion of NIS increased IFN $\gamma$ signaling and affected downstream pathways including the JAK-STAT, MAPK, and NF-kB pathways in GC cells.

NIS was initially identified in several normal tissues, namely thyroid, salivary gland, stomach, and mammary gland [28], and our investigation also showed its remarkable expression in normal gastric mucosa (Fig. 4a; Supplementary Figs. 1b, 4). NIS protein was expressed on the basolateral membrane in normal gastric mucosa cells, and transferred $\mathrm{I}^{-}$from the bloodstream into the gastrointestinal tract $[3,6,7]$. On the other hand, immunohistochemistry with samples revealed that the NIS protein was mainly expressed in the cytoplasm of carcinoma cells. Although further investigations are needed, these results suggest that this new regulatory mechanism of IFN signaling is mostly conducted by the intracellular fraction of NIS rather than transmembrane $\mathrm{Na}^{+} / \mathrm{I}^{-}$transport. In this manner, the strong expression of NIS protein in cytoplasm may be associated with poor prognosis of GCs.

Recent studies on NIS in cancer mainly focused on radioiodine therapy $[2,10]$. Radioiodide uptake has been sporadically reported not only in thyroid carcinoma, but also in breast, gastric, and lung carcinomas [28, 37]. The stimulation of NIS expression is considered to be necessary to increase radioiodide uptake into cancer cells that is sufficient for therapy. Previous studies demonstrated that the inhibition of the histone deacetylase (HDAC), MAPK, or PI3K/Akt pathway may induce the expression of NIS, and thus, it has the potential to become a novel therapeutic approach promoting greater radioiodine uptake by cancer cells $[31,32$, 38, 39]. Furthermore, NIS gene therapy has been investigated to increase radioiodide accumulation in cancer cells $[2,10]$. In GC, simultaneously suppressing the MAPK, PI3K/Akt pathways and HDAC could induce strong NIS expression and radioiodine uptake in MKN7 cells, providing novel therapeutic implications for radioiodine treatment [40]. Our immunohistochemistry results revealed that strong NIS expression was a poor prognostic factor for GC patients, and therefore, radioiodine therapy may become a valid option for patients with the strong expression of NIS on cell membranes. On the other hand, the present results indicated that the depletion of NIS itself exerted inhibitory effects on tumor behavior, such as cell proliferation, survival and invasion, suggesting that NIS has potential as a key therapeutic target and that the silencing of its expression provides a novel therapeutic strategy in the future.

In summary, we herein demonstrated that NIS played a role in the proliferation, survival, migration, and invasion of GC cells. Our microarray results suggest that NIS markedly affects the expression of genes related to IFN signaling and downstream pathways including the JAK-STAT, MAPK, and NF-kB pathways. The results of the immunohistochemical analysis also revealed that the strong expression of NIS was a valuable poor prognostic factor in patients with GC. A deeper understanding of the role of NIS may lead to its use as an important biomarker of tumor development and/or a novel therapeutic target for GC. 
Table 3 Prognostic factors of gastric cancer according to univariate and multivariate analyses

\begin{tabular}{|c|c|c|c|c|c|}
\hline \multirow[t]{2}{*}{ Variables } & \multicolumn{2}{|l|}{ Univariate } & \multicolumn{3}{|c|}{ Multivariate } \\
\hline & $\begin{array}{l}\text { 5-year survival } \\
\text { rate }(\%)\end{array}$ & $p$ value & Risk ratio & $95 \% \mathrm{CI}$ & $p$ value \\
\hline \multicolumn{6}{|l|}{ Gender } \\
\hline Male & 75 & 0.8658 & & & \\
\hline Female & 75.1 & & & & \\
\hline \multicolumn{6}{|l|}{ Age } \\
\hline$\leq 65$ & 81.4 & $0.0412 *$ & Ref & & $0.0318^{\#}$ \\
\hline$>65$ & 66.1 & & 2.344 & $1.076-5.272$ & \\
\hline \multicolumn{6}{|l|}{ Histological type } \\
\hline Differentiated & 74.6 & 0.918 & & & \\
\hline Undifferentiated & 75.4 & & & & \\
\hline \multicolumn{6}{|l|}{ Lymphatic invasion } \\
\hline Negative & 95 & $0.0001 *$ & Ref & & 0.8762 \\
\hline Positive & 53.7 & & 1.11 & $0.336-5.186$ & \\
\hline \multicolumn{6}{|l|}{ Venous invasion } \\
\hline Negative & 90.1 & $0.0001^{*}$ & Ref & & 0.0645 \\
\hline Positive & 42.3 & & 2.18 & $0.955-5.490$ & \\
\hline \multicolumn{6}{|l|}{ pT } \\
\hline pT1 & 98.2 & $0.0001 *$ & Ref & & $0.004^{\#}$ \\
\hline pT2-4 & 46.1 & & 12.822 & $2.009-257.002$ & \\
\hline \multicolumn{6}{|l|}{$\mathrm{pN}$} \\
\hline $\mathrm{pN} 0$ & 94.5 & $0.0001 *$ & Ref & & $0.0017^{\#}$ \\
\hline $\mathrm{pN} 1-3$ & 39.8 & & 5.351 & $1.781-21.329$ & \\
\hline \multicolumn{6}{|l|}{ NIS expression } \\
\hline Low group & 82.9 & $0.0041 *$ & Ref & & $0.0101^{\#}$ \\
\hline High group & 60.9 & & 2.768 & $1.276-6.086$ & \\
\hline
\end{tabular}

$p T$ pathological T stage, $p N$ pathological N stage, Ref referent

$* p<0.05$ : Log-rank test

${ }^{\#} p<0.05$ : Cox's proportional hazards model; 95\% CI 95\% confidence interval
Acknowledgements This work was supported by Grants-in-Aid for Scientific Research (C) (17K10602) and a Grant-in-Aid for Young Scientists (B) (17K16576) from the Japan Society for the Promotion of Science.

\section{Compliance with ethical standards}

Conflict of interest The authors declare that they have no conflict of interest.

Ethical statement All procedures followed were in accordance with the ethical standards of the responsible committee on human experimentation (institutional and national) and with the Helsinki Declaration of 1964 and later versions. Informed consent to be included in the study, or the equivalent, was obtained from all patients.

\section{References}

1. Dai G, Levy O, Carrasco N. Cloning and characterization of the thyroid iodide transporter. Nature. 1996;379:458-60.
2. Micali S, Bulotta S, Puppin C, Territo A, Navarra M, Bianchi G, Damante G, Filetti S, Russo D. Sodium iodide symporter (NIS) in extrathyroidal malignancies: focus on breast and urological cancer. BMC Cancer. 2014;14:303.

3. Dohan O, De la Vieja A, Paroder V, Riedel C, Artani M, Reed M, Ginter CS, Carrasco N. The sodium/iodide symporter (NIS): characterization, regulation, and medical significance. Endocr Rev. 2003;24:48-77.

4. Postiglione MP, Parlato R, Rodriguez-Mallon A, Rosica A, Mithbaokar P, Maresca M, Marians RC, Davies TF, Zannini MS, De Felice M, Di Lauro R. Role of the thyroid-stimulating hormone receptor signaling in development and differentiation of the thyroid gland. Proc Natl Acad Sci USA. 2002;99:15462-7.

5. Kogai T, Taki K, Brent GA. Enhancement of sodium/iodide symporter expression in thyroid and breast cancer. Endocr Relat Cancer. 2006;13:797-826

6. Josefsson M, Grunditz T, Ohlsson T, Ekblad E. Sodium/ iodide-symporter: distribution in different mammals and role in entero-thyroid circulation of iodide. Acta Physiol Scand. 2002;175:129-37.

7. Nicola JP, Basquin C, Portulano C, Reyna-Neyra A, Paroder M, Carrasco $\mathrm{N}$. The $\mathrm{Na}^{+} / \mathrm{I}^{-}$symporter mediates active iodide uptake in the intestine. Am J Physiol Cell Physiol. 2009;296:C654-62. 
8. De La Vieja A, Dohan O, Levy O, Carrasco N. Molecular analysis of the sodium/iodide symporter: impact on thyroid and extrathyroid pathophysiology. Physiol Rev. 2000;80:1083-105.

9. Liu XH, Chen GG, Vlantis AC, van Hasselt CA. Iodine mediated mechanisms and thyroid carcinoma. Crit Rev Clin Lab Sci. 2009;46:302-18.

10. Kogai T, Brent GA. The sodium iodide symporter (NIS): regulation and approaches to targeting for cancer therapeutics. Pharmacol Ther. 2012;135:355-70.

11. Poole VL, McCabe CJ. Iodide transport and breast cancer. J Endocrinol. 2015;227:R1-12.

12. Riesco-Eizaguirre G, Leoni SG, Mendiola M, Estevez-Cebrero MA, Gallego MI, Redondo A, Hardisson D, Santisteban P, De la Vieja A. NIS mediates iodide uptake in the female reproductive tract and is a poor prognostic factor in ovarian cancer. J Clin Endocrinol Metab. 2014;99:E1199-208.

13. Jeon YH, Lee HW, Lee YL, Kim JE, Hwang MH, Jeong SY, Lee SW, Ahn BC, Ha JH, Lee J. Combined E7-dendritic cell-based immunotherapy and human sodium/iodide symporter radioiodine gene therapy with monitoring of antitumor effects by bioluminescent imaging in a mouse model of uterine cervical cancer. Cancer Biother Radiopharm. 2011;26:671-9.

14. Navarra M, Micali S, Lepore SM, Cesinaro AM, Celano M, Sighinolfi MC, De Gaetani C, Filetti S, Bianchi G, Russo D. Expression of the sodium/iodide symporter in human prostate adenocarcinoma. Urology. 2010;75:773-8.

15. Micali S, Maggisano V, Cesinaro A, Celano M, Territo A, Reggiani Bonetti L, Sponziello M, Migaldi M, Navarra M, Bianchi G, Filetti $\mathrm{S}$, Russo D. Sodium/iodide symporter is expressed in the majority of seminomas and embryonal testicular carcinomas. J Endocrinol. 2013;216:125-33.

16. Jeon YH, Ahn SJ, Lee YJ, Lee YL, Lee SW, Park SY, Kim IS, Ahn BC, Ha JH, Lee J. Human sodium iodide symporter added to multidrug resistance 1 small hairpin RNA in a single gene construct enhances the therapeutic effects of radioiodine in a nude mouse model of multidrug resistant colon cancer. Cancer Biother Radiopharm. 2010;25:671-9.

17. Dwyer RM, Bergert ER, O'Connor MK, Gendler SJ, Morris JC. Adenovirus-mediated and targeted expression of the sodium-iodide symporter permits in vivo radioiodide imaging and therapy of pancreatic tumors. Hum Gene Ther. 2006;17:661-8.

18. Shiozaki A, Kudou M, Ichikawa D, Shimizu H, Arita T, Kosuga T, Konishi H, Komatsu S, Fujiwara H, Okamoto K, Kishimoto M, Marunaka Y, Otsuji E. Expression and role of anion exchanger 1 in esophageal squamous cell carcinoma. Oncotarget. 2017;8:17921-35.

19. Ariyoshi Y, Shiozaki A, Ichikawa D, Shimizu H, Kosuga T, Konishi H, Komatsu S, Fujiwara H, Okamoto K, Kishimoto M, Marunaka Y, Otsuji E. $\mathrm{Na}^{+} / \mathrm{H}^{+}$exchanger 1 has tumor suppressive activity and prognostic value in esophageal squamous cell carcinoma. Oncotarget. 2017;8:2209-23.

20. Shiozaki A, Kudou M, Ichikawa D, Fujiwara H, Shimizu H, Ishimoto T, Arita T, Kosuga T, Konishi H, Komatsu S, Okamoto K, Marunaka Y, Otsuji E. Esophageal cancer stem cells are suppressed by tranilast, a TRPV2 channel inhibitor. J Gastroenterol. 2018;53:197-207.

21. Shimizu H, Shiozaki A, Ichikawa D, Fujiwara H, Konishi H, Ishii H, Komatsu S, Kubota T, Okamoto K, Kishimoto M, Otsuji E. The expression and role of Aquaporin 5 in esophageal squamous cell carcinoma. J Gastroenterol. 2014;49:655-66.

22. Shiozaki A, Nako Y, Ichikawa D, Konishi H, Komatsu S, Kubota T, Fujiwara H, Okamoto K, Kishimoto M, Marunaka Y, Otsuji E. Role of the $\mathrm{Na}^{+} / \mathrm{K}^{+} / 2 \mathrm{Cl}^{-}$cotransporter $\mathrm{NKCC} 1$ in cell cycle progression in human esophageal squamous cell carcinoma. World J Gastroenterol. 2014;20:6844-59.

23. Shiozaki A, Ichikawa D, Otsuji E, Marunaka Y. Cellular physiological approach for treatment of gastric cancer. World J Gastroenterol. 2014;20:11560-6.
24. Sobin LH, Compton CC. TNM seventh edition: what's new, what's changed: communication from the International Union Against Cancer and the American Joint Committee on Cancer. Cancer. 2010;116:5336-9.

25. Remmele W, Stegner HE. Recommendation for uniform definition of an immunoreactive score (IRS) for immunohistochemical estrogen receptor detection (ER-ICA) in breast cancer tissue. Pathology. 1987;8:138-40.

26. Gough DJ, Levy DE, Johnstone RW, Clarke CJ. IFNgamma signaling-does it mean JAK-STAT? Cytokine Growth Factor Rev. 2008;19:383-94.

27. Saleiro D, Kosciuczuk EM, Platanias LC. Beyond autophagy: new roles for ULK1 in immune signaling and interferon responses. Cytokine Growth Factor Rev. 2016;29:17-22.

28. Wapnir IL, van de Rijn M, Nowels K, Amenta PS, Walton K, Montgomery K, Greco RS, Dohan O, Carrasco N. Immunohistochemical profile of the sodium/iodide symporter in thyroid, breast, and other carcinomas using high density tissue microarrays and conventional sections. J Clin Endocrinol Metab. 2003;88:1880-8.

29. Lacoste C, Herve J, Bou Nader M, Dos Santos A, Moniaux N, Valogne Y, Montjean R, Dorseuil O, Samuel D, Cassio D, Portulano C, Carrasco N, Brechot C, Faivre J. Iodide transporter NIS regulates cancer cell motility and invasiveness by interacting with the Rho guanine nucleotide exchange factor LARG. Cancer Res. 2012;72:5505-15.

30. Dentice M, Luongo C, Elefante A, Romino R, Ambrosio R, Vitale M, Rossi G, Fenzi G, Salvatore D. Transcription factor Nkx-2.5 induces sodium/iodide symporter gene expression and participates in retinoic acid- and lactation-induced transcription in mammary cells. Mol Cell Biol. 2004;24:7863-77.

31. Kogai T, Schultz JJ, Johnson LS, Huang M, Brent GA. Retinoic acid induces sodium/iodide symporter gene expression and radioiodide uptake in the MCF-7 breast cancer cell line. Proc Natl Acad Sci USA. 2000;97:8519-24.

32. Ohashi E, Kogai T, Kagechika H, Brent GA. Activation of the PI3 kinase pathway by retinoic acid mediates sodium/iodide symporter induction and iodide transport in MCF-7 breast cancer cells. Cancer Res. 2009;69:3443-50.

33. Fish EN. Platanias LC2. Interferon receptor signaling in malignancy: a network of cellular pathways defining biological outcomes. Mol Cancer Res. 2014;12:1691-703.

34. Wack A, Terczynska-Dyla E, Hartmann R. Guarding the frontiers: the biology of type III interferons. Nat Immunol. 2015;16:802-9.

35. Sun D, Ding A. MyD88-mediated stabilization of interferongamma-induced cytokine and chemokine mRNA. Nat Immunol. 2006;7:375-81.

36. Kawai T, Akira S. TLR signaling. Semin Immunol. 2007;19:24-32.

37. Wu SY, Kollin J, Coodley E, Lockyer T, Lyons KP, Moran E, Parker LN, Yu AC. I-131 total-body scan: localization of disseminated gastric adenocarcinoma. Case report and survey of the literature. J Nucl Med. 1984;25:1204-9.

38. Kitazono M, Robey R, Zhan Z, Sarlis NJ, Skarulis MC, Aikou T, Bates S, Fojo T. Low concentrations of the histone deacetylase inhibitor, depsipeptide (FR901228), increase expression of the $\mathrm{Na}(+) / \mathrm{I}(-)$ symporter and iodine accumulation in poorly differentiated thyroid carcinoma cells. J Clin Endocrinol Metab. 2001;86:3430-5.

39. Zarnegar R, Brunaud L, Kanauchi H, Wong M, Fung M, Ginzinger $\mathrm{D}$, Duh QY, Clark OH. Increasing the effectiveness of radioactive iodine therapy in the treatment of thyroid cancer using Trichostatin A, a histone deacetylase inhibitor. Surgery. 2002;132:984-90.

40. Liu Z, Xing M. Induction of sodium/iodide symporter (NIS) expression and radioiodine uptake in non-thyroid cancer cells. PLoS One. 2012;7:e31729. 